\title{
The Tide Effects on Bioeconomic Model of Sardina pilchardus, Engraulis encrasicolus and Xiphias gladius in Atlantic Moroccan Zone
}

\author{
Nossaiba Baba ${ }^{1}$ (D) $\cdot$ Imane Agmour $^{1}$. Youssef El Foutayeni ${ }^{1,2} \cdot$ Naceur Achtaich $^{1}$
}

Received: 20 April 2021 / Revised: 15 May 2021 / Accepted: 19 May 2021 / Published online: 10 June 2021

(c) The Author(s) 2021

\begin{abstract}
The main objective of this work is the study of the effects of high tides and low tides on fishing effort, catches as well as profits in a bioeconomic model of populations of Sardina pilchardus, Engraulis encrasicolus and Xiphias gladius in Moroccan areas. To achieve this objective, we studied the stability of the equilibrium points of our biological model then we added in our model the effect of the tides in the fishing effort which maximizes the profits of the fishermen under the constraint of the conservation of the biodiversity of these marine species using the generalized Nash equilibrium in the resolution of the bioeconomic model. As results, we were able to give the best fishing times according to the tides of each month of the whole year which will allow us to achieve better yields. Hence the importance of introducing the effect of high and low tides in bioeconomic models.
\end{abstract}

Keywords Bioeconomic model $\cdot$ Fish populations $\cdot$ High tides $\cdot$ Low tides $\cdot$ Nash equilibrium

\section{Introduction}

The fishing industry in Morocco is one of the main sources of foreign exchange, accounting for $2.84 \%$ of total exports. The industry has long been an economic pillar for the country. This has allowed the kingdom to be considered the largest fish market in Africa.

The tide is the variation in the height of sea and ocean level, caused by the combination of gravitational forces due to the Moon and the Sun and the rotation of the Earth. During the full moon and the new moon, that is to say when the Earth, the Moon and the Sun are approximately in the same axis (we speak of syzygy), the influence of the celestial bodies is added and the tides are of greater amplitude (spring tides). On the contrary, during the first and last quarters, when the three bodies are in quadrature, the amplitude is lower (neapolitan).

The current of rising tide is called ebb or flow, the current of ebbing tide is called ebb. Depending on the location

Nossaiba Baba

noussaibababa1@gmail.com

1 Analysis, Modeling and Simulation Laboratory, Hassan II University, Casablanca, Morocco

2 Unit for Mathematical and Computer Modeling of Complex Systems, IRD, Bondy Cedex, France of the Earth, the ebb and flow cycle can take place once (diurnal tide) or twice a day (semi-diurnal tide) 3 or be of a mixed type.

The highest level reached by the sea during a tidal cycle is called high tide (or commonly high tide). In contrast, the lowest level is called low tide (or low tide). When the sea has reached its highest or lowest level and seems to be no longer moving, the sea is said to be slack. Speaking of "high tide" and "low tide" is most common, although the word tide normally refers to movement.

The lowest tides of the year normally occur at the winter and summer solstices, the strongest at the spring and fall equinoxes.

High tides are highly beneficial for the fishing of many fish. Since the current "hits" at the break, the seabed and the marine nutrients are stirred. This phenomenon therefore attracts many fish which take advantage of these tides to feed themselves.

Fish like sea bass or sea bream hang out here to hunt. They also take advantage of the current of the rising tide to enter baïnes (kinds of cavities between sandbanks) to feed themselves, so it is easier to catch them. In such conditions, the hooked line of a resistant bait (e.g.,: cuttlefish) can remain in place for several hours;

The high tides are suitable for both sea and water fishing. In the sand, you can fish for razor clams, clams, clams, 
scallops, and in the rocks spider, curry, shrimp, crab or crab and for the bravest conger.

At ebb tide, the bottom of a baines will undoubtedly not be productive, but its inlet can shelter fine fish if there is food there. The fish "wait at the exit" for the current to bring their meal directly to them. It is certainly a moment not to be missed, especially for spotting. Indeed, the discovery beach makes it possible to prospect the places. It is often the only time to go fishing in a deep or a distant pit.

The management of renewable resources has been the subject of an abundant literature in the case of marine resources the first works in this direction come back to (Schaefer 1954, 1957; Quinn and Deriso 1999; Haddon 2001; Gordon 1954; Clarke and Munro 1991, 1975) where the authors worked by simple economic models of exploitation of the fishing grounds. Recently, several authors have studied bioeconomic models for the exploitation of marine resources, citing as an example (Agmour et al. 2020), where the authors, in this work, studied the influence of the wind speed on the annual fishing effort, catches and profit of seiners, and show that these parameters are the most important parameters involved in seiner's fishing activity. In (Bentounsi et al. 2018), the authors studied the effect of the variation of the price on each profit. We can cite also (Baba et al. 2019), where the authors study the influence of the predator mortality rate variation on the evolution of prey biomass and the profit of coastal trawlers in a bioeconomic model of Parapenaeus longirostris population and the small pelagic species in protected area and unprotected area.

In the literature, several bioeconomic models have been studied and developed but without taking into account the effect of high and low tides in their models. Our contribution will then be to include tidal effects in the study and modeling of bioeconomic models, to give more relevant results and closer to reality. For that, we consider a bioeconomic model of the evolution of three marine species: Sardina pilchardus, Engraulis encrasicolus and Xiphias gladius.

The Sardina pilchardus is a species of fish from the Clupeidae family depending on the region. It is the only species of its kind. This fish lives in the Mediterranean where it is the second most caught fish (16\%) among the "small pelagics" (which constitute $50 \%$ of the total catch) and in almost the entire North Atlantic (Figs. 1, 2). In Morocco, more than $62 \%$ of the tonnage landed by the country's coastal fleet. The stock of sardines traditionally taken north of El Ayoun is considered by the FAO to be "intensely exploited" and that located between Capes Bojador and Barbas is "fully exploited", which raises the question of overexploitation and sustainability of this fishing in this area. The Engraulis encrasicolus is a species of marine fish belonging to the family Engraulidae. Mainly fished by pelagic trawl and purse seine, it shoals in coastal areas and is found up to $150 \mathrm{~m}$ deep. The common anchovy is present throughout

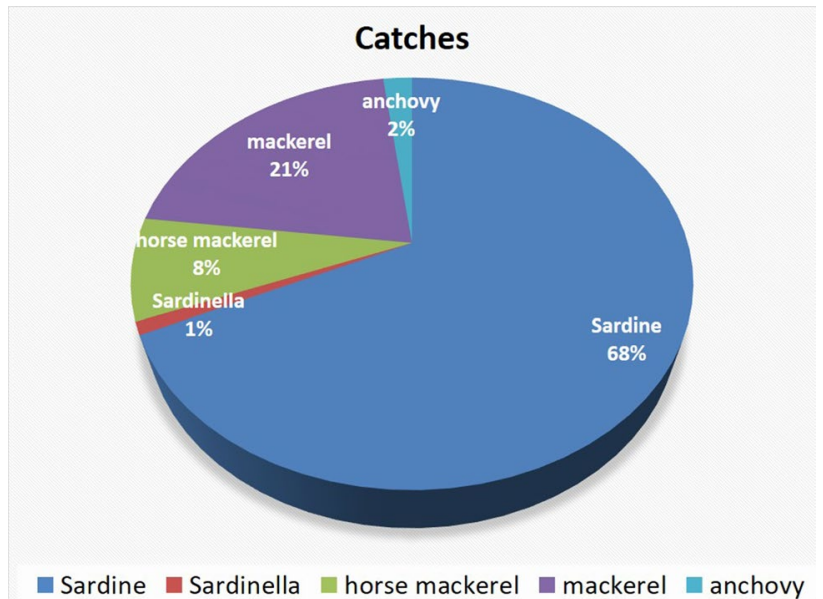

Fig. 1 Catches made by type of species

the Atlantic and is also widespread throughout the Mediterranean basin.

Xiphias gladius is a species of pelagic fish from tropical

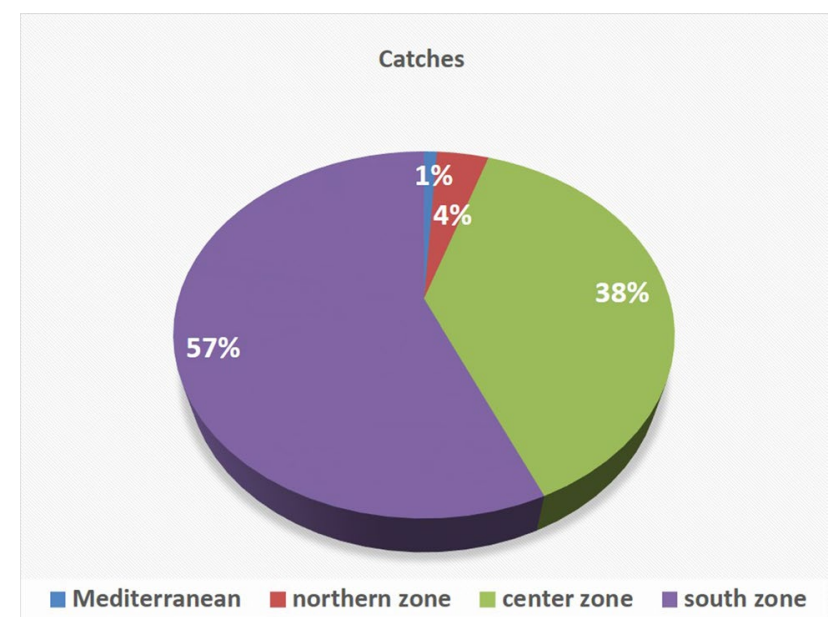

Fig. 2 Catches made by zones

and temperate seas, unique representative of the Xiphiidae family. It can exceed $2 \mathrm{~m}$ in length and weigh more than $100 \mathrm{~kg}$. It has a long rather flattened "beak" (the rostrum) which represents a third of the total length of the animal. The swordfish feeds on squid and fish. It can reach $90 \mathrm{~km} / \mathrm{h}$ $(24.9 \mathrm{~m} / \mathrm{s})$ at top speed. Xiphias gladius is a pelagic fish, mainly oceanic, which generally lives between 200 and $600 \mathrm{~m}$ of depth and in waters with a temperature between 18 and $22^{\circ} \mathrm{C} 3$.

It is found in tropical and temperate oceans around the world. It is thus present in the Atlantic oceans, as well as in seas such as the Mediterranean Sea. 
These marine species are supposed to be exploited by seiners on the Moroccan coast. Our main objective is the calculation of fishing effort which allows the purse seiners to achieve maximum annual profit while taking into account two constraints: the effects of tidal changes and the conservation of the biodiversity of marine species.

The organization of this paper is as follows: In Biological model Description, Formulation, and Analysis section, we give the biological model's presentation then we determine the interior equilibrium point, and we study its stability. In "Profit Maximization" section, we give the bioeconomic model and the mathematical formula of the profit of purse seiners under Tide effects after that, we calculate the maximum fishing effort of seiners. In the next section "Numerical Simulation" we discuss the results obtained and we compare it with the data from the INRH. At the end, we close our paper with the a conclusion.

\section{Biological Model Description, Formulation, and Analysis}

The mathematical model (1) describes the evolution of the biomass of three fish populations: Sardina pilchardus, Engraulis encrasicolus, Xiphias gladius in Moroccan areas. We assume that the two populations Sardina pilchardus and Engraulis encrasicolus compete with each other for food or space and they are both prey for the population of Xiphias gladius. The Sardina pilchardus abundance is denoted by $S(t)$. It grows according to a logistic equation where $r_{1}$ is the growth rate per capita and $K_{1}$ is the carrying capacity. The Engraulis encrasicolus abundance is denoted by $E(t)$. It grows according to a logistic equation with per capita growth rate constant $r_{2}$ and carrying capacity $K_{2}$. They compete with each other for space or food; the parameters $c_{12}, c_{21}$ represent the competition coefficients between these two marine populations. The Xiphias gladius abundance is denoted by $X(t)$. It's have a natural death rates $d$. The Sardina pilchardus and the Engraulis encrasicolus are among the best food for Xiphias gladius populations. So, we denote by $\delta_{1}$ and $\delta_{2}$ the capture coefficients of Sardina pilchardus and Engraulis encrasicolus by Xiphias gladius populations, respectively. The parameters $\alpha, \beta$ are the conservation coefficients of Xiphias gladius biomass into Sardina pilchardus and Engraulis encrasicolus populations (see Fig. 3).

Following the previous assumptions, the biological model is formulated as follow:

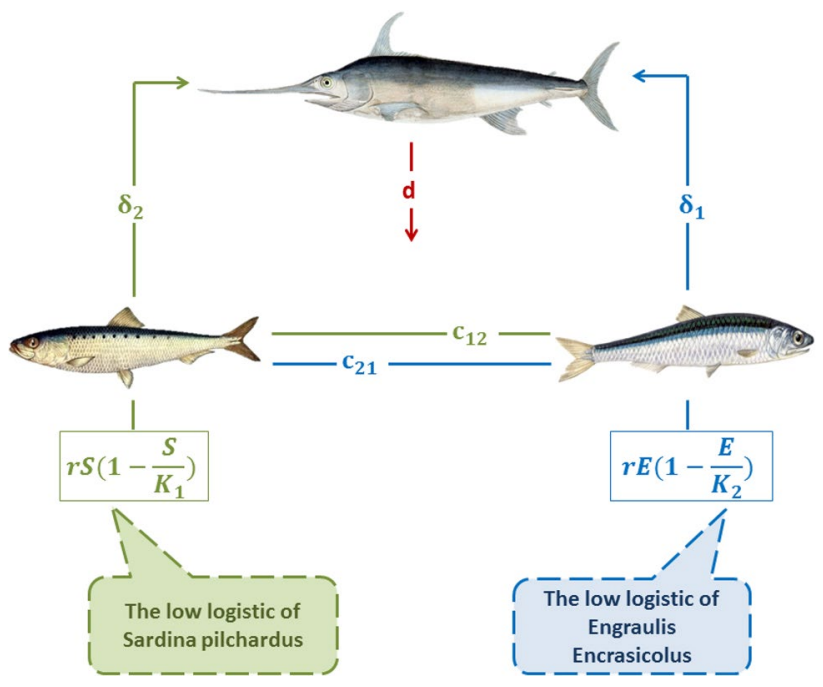

Fig. 3 The interaction between the Sardina pilchardus, Engraulis Encrasicolus and Xiphias gladius fish populations

$\left\{\begin{array}{l}\dot{S}(t)=r_{1} S(t)\left(1-\frac{S(t)}{K_{1}}\right)-c_{12} S(t) E(t)-\delta_{1} X(t) S(t) \\ \dot{E}(t)=r_{2} E(t)\left(1-\frac{E(t)}{K_{2}}\right)-c_{21} S(t) E(t)-\delta_{2} X(t) E(t) \\ \dot{X}(t)=\alpha \delta_{1} X(t) S(t)+\beta \delta_{2} X(t) E(t)-d X(t)\end{array}\right.$

with initial conditions, $S(0)>0, E(0)>0$ and $X(0)>0$.

The possible equilibria of the dynamical system (1) are:

$\left\{\begin{array}{l}P_{1}(0,0,0), \\ p_{2}\left(0, \frac{K_{2} r_{1} r_{2}-K_{1} K_{2} r_{1} c_{21}}{r_{1} r_{2}-K_{1} K_{2} c_{12} c_{21}}, \frac{K_{1} r_{1} r_{2}-K_{1} K_{2} r_{2} c_{12}}{r_{1} r_{2}-K_{1} K_{2} c_{12} c_{21}}\right), \\ P_{3}\left(\frac{r_{1} r_{2}-K_{1} r_{1} c_{21}}{\delta_{2} r_{1}-\delta_{1} K_{1} c_{21}}, 0,-\frac{\delta_{1} K_{1} r_{2}-\delta_{2} K_{1} r_{1}}{\delta_{2} r_{1}-\delta_{1} K_{1} c_{21}}\right), \\ P_{4}\left(\frac{r_{1} r_{2}-K_{2} r_{2} c_{12}}{\delta_{1} r_{2}-\delta_{2} K_{2} c_{12}}, \frac{\delta_{1} K_{2} r_{2}-\delta_{2} K_{2} r_{1}}{\delta_{1} r_{2}-\delta_{2} K_{2} c_{12}}, 0\right), \\ P_{5}\left(0,0, K_{1}\right), \\ P_{6}\left(0, \frac{r_{1}}{c_{12}}, 0\right), \\ P_{7}\left(\frac{r_{1}}{\delta_{1}}, 0,0\right) \\ P_{8}\left(S^{*}, E^{*}, X^{*}\right)\end{array}\right.$

where 


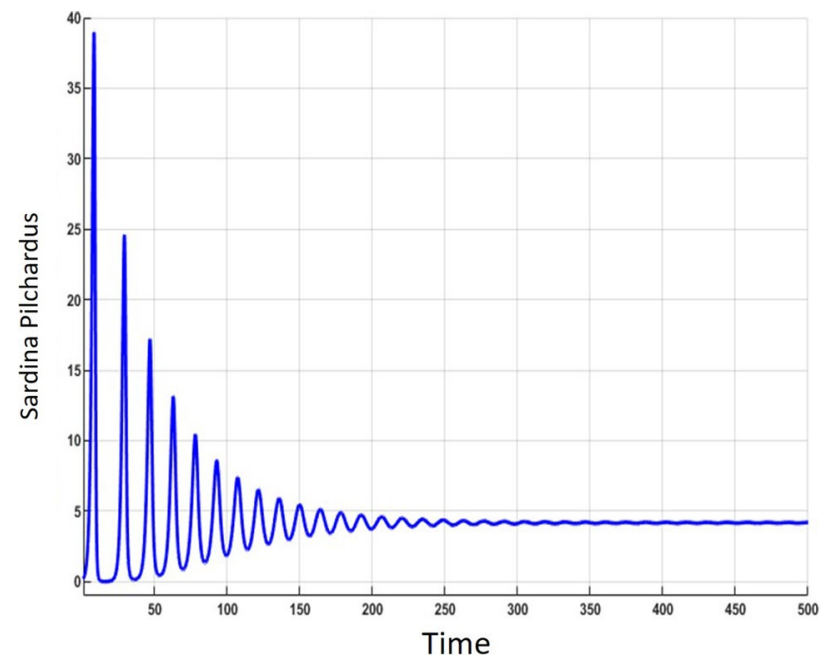

Fig. 4 Dynamical behavior of Sardina pilchardus

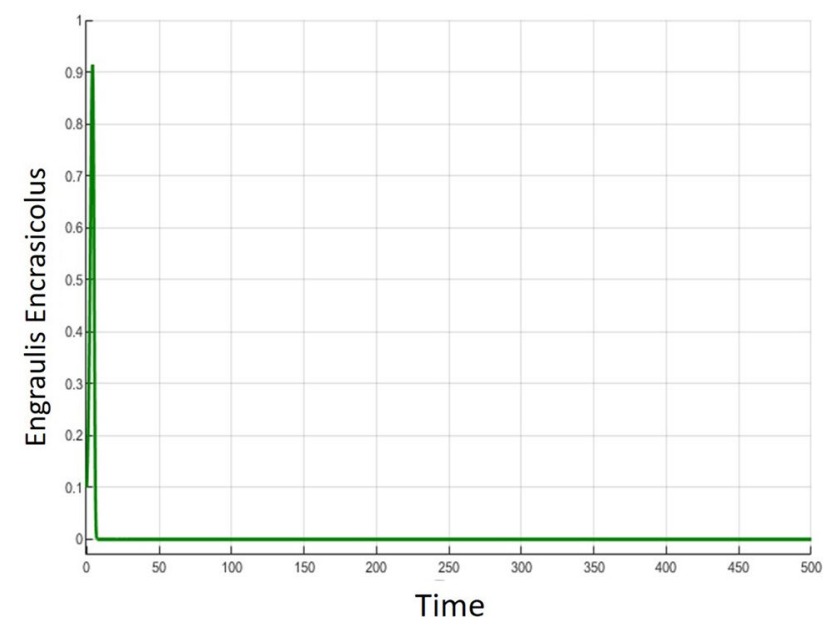

Fig. 5 Dynamical behavior of Engraulis encrasicolus

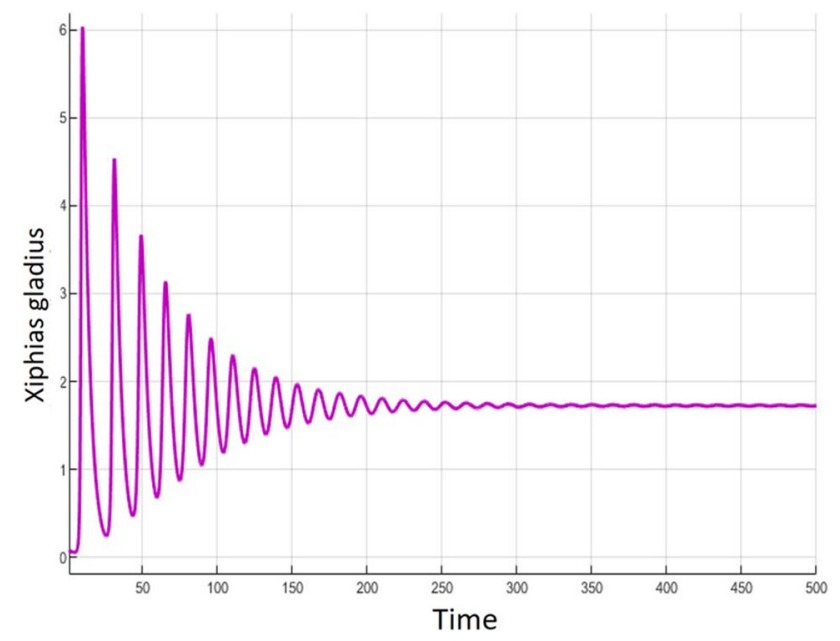

Fig. 6 Dynamical behavior of Xiphias gladius

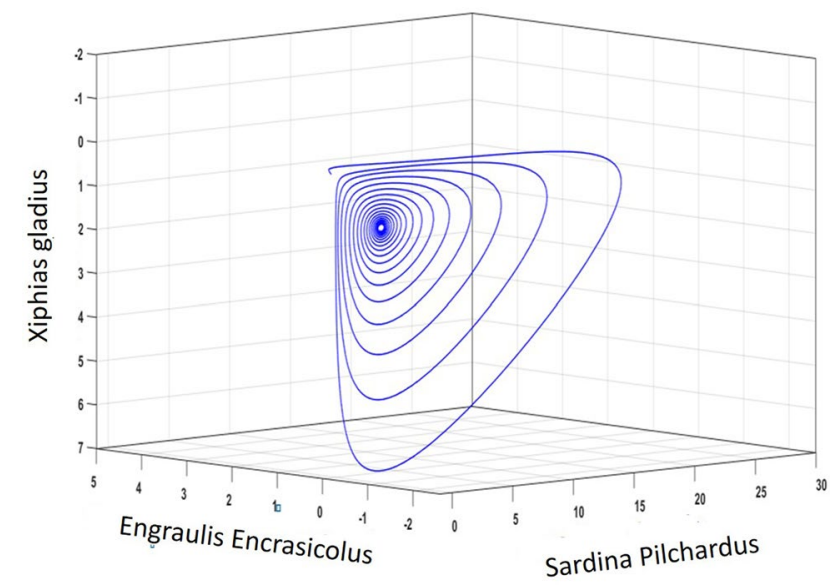

Fig. 7 Dynamical behavior of Sardina pilchardus, Engraulis Encrasicolus and Xiphias gladius fish populations

$$
\left\{\begin{aligned}
X^{*} & =\frac{d K_{1} K_{2} c_{12} c_{21}+\alpha \delta_{1} K_{1} r_{1} r_{2}+\beta \delta_{2} K_{2} r_{1} r_{2}-d r_{1} r_{2}-\alpha \delta_{1} K_{1} K_{2} r_{2} c_{12}-\beta \delta_{2} K_{1} K_{2} r_{1} c_{21}}{\alpha \delta_{1} K_{1}\left(\delta_{1} r_{2}-\delta_{2} K_{2} c_{12}\right)+\beta \delta_{2} K_{2}\left(\delta_{2} r_{1}-\delta_{1} K_{1} c_{21}\right)} \\
E^{*}= & \frac{d K_{2}\left(\delta_{2} r_{1}-\delta_{1} K_{1} c_{21}\right)+\alpha \delta_{1} K_{1} K_{2}\left(\delta_{1} r_{2}-\delta_{2} r_{1}\right)}{\alpha \delta_{1} K_{1}\left(\delta_{1} r_{2}-\delta_{2} K_{2} c_{12}\right)+\beta \delta_{2} K_{2}\left(\delta_{2} r_{1}-\delta_{1} K_{1} c_{21}\right)} \\
S^{*}= & \frac{d \delta_{1} K_{1} r_{2}-d \delta_{2} K_{1} K_{2} c_{12}+\beta \delta_{2}^{2} K_{1} K_{2} r_{1}-\beta \delta_{1} \delta_{2} K_{1} K_{2} r_{2}}{\alpha \delta_{1} K_{1}\left(\delta_{1} r_{2}-\delta_{2} K_{2} c_{12}\right)+\beta \delta_{2} K_{2}\left(\delta_{2} r_{1}-\delta_{1} K_{1} c_{21}\right)}
\end{aligned}\right.
$$

In this work, we give a growing interest to the last interior equilibrium point. Because this last one, ensures the coexistence of the biomass of the three fish populations under the following conditions of existence $\delta_{1} r_{2}>\delta_{2} K_{2} c_{12}$ et $\delta_{1} r_{2}>\delta_{2} r_{1}>\delta_{1} K_{1} c_{21}(*)$

At the interior equilibrium point $P_{8}\left(S^{*}, E^{*}, X^{*}\right)$, the variational matrix of the mathematical model (1) is as follow:
$M(P)=\left[\begin{array}{lll}-\frac{r_{1}}{K_{1}} S^{*} & -c_{12} S^{*} & -\delta_{1} S^{*} \\ -c_{21} E^{*} & -\frac{r_{2}}{K_{2}} E^{*} & -\delta_{2} E^{*} \\ \alpha \delta_{1} X^{*} & \beta \delta_{2} X^{*} & 0\end{array}\right]$

The characteristic polynomial associated to the variational matrix is written as: $P(\lambda)=a_{3} \lambda^{3}+a_{2} \lambda^{2}+a_{1} \lambda+a_{0}$ where 


$$
\left\{\begin{aligned}
a_{3} & =1 \\
a_{2} & =\frac{r_{2}}{K_{2}} E^{*}+\frac{r_{1}}{K_{1}} S^{*} \\
a_{1} & =\left(\frac{r_{1} r_{2}}{K_{1} K_{2}}-c_{12} c_{21}\right) E^{*} S^{*}+\beta \delta_{2}^{2} E^{*} X^{*}+\alpha \delta_{1}^{2} S^{*} X^{*} \\
a_{0} & =-\alpha \delta_{1} X^{*} S^{*}\left(\delta_{2} c_{12} E^{*}+\delta_{1} r_{1} S^{*}\right)+\left(\alpha \delta_{1}^{2} S^{*} X^{*}-\beta \delta_{2}^{2} E^{*} X^{*}\right) \\
& \times\left(r_{1} S^{*}+\frac{r_{2}}{K_{2}} E^{*}\right)+\beta \delta_{2} \frac{\delta_{2} r_{2}}{K_{2}}\left(E^{*}\right)^{2}+\delta_{1} c_{21} E^{*} S^{*} X^{*}
\end{aligned}\right.
$$

We have $a_{2}>0$ and $a_{1} a_{2}>a_{0}$ with $a_{0}>0$ under the coditions of existence. So, using the criterion of Routh-Hurwitz stability (Baba et al. 2021), we deduce that the equilibrium point $P_{8}\left(S^{*}, E^{*}, X^{*}\right)$ is stable.

Beginning with parameters $r_{1}=0.9, r_{2}=0.8, K_{1}=100$, $K_{2}=192, c_{12}=0.0 Q_{21}=0.1, \alpha=0.11, \beta=0.32, d=0.23$, $\delta_{1}=0.5$ and $\delta_{2}=0.21$ and initial value $(0.1,0.1,0.1)$ the point $P_{8}$ tend to the point $\left(4.96,1.64 \times 10^{-26}, 1.89\right)$. The Figures $(4,5,6,7)$ shows the dynamical behavior of the Sardina pilchardus, Engraulis encrasicolus and Xiphias gladius populations. It can be seen that the biomass of these three marine species converges towards the values of the interior equilibrium point. This can be biologically interpreted that the interior point of equilibrium ensures the existence of predefined species.

\section{Profit Maximization}

We now consider the bioeconomic model of the population of the marine species of Sardina pilchardus, Engraulis encrasicolus and Xiphias gladius, this time introducing the fishing activity of purse seine fleets in Moroccan areas. The bioeconomic system (2) is formulated using the GordonScafear catchability coefficient $H_{i}=q_{i} F_{i} Y_{i}$, where $q_{i}$ represent the catchability coefficient of species $i, F_{i}$ represent the fishing effort dedicated to exploit species $i$ and $Y_{i}$ represent the biomass of Sardina pilchardus, Engraulis encrasicolus and Xiphias gladius. The differential equations system is as follow:

$$
\left\{\begin{array}{l}
\dot{S}(t)=r_{1} S(t)\left(1-\frac{S(t)}{K_{1}}\right)-\sigma_{12} S(t) E(t)-\delta_{1} X(t) S(t)-q_{1} F_{1} S(t) \\
\dot{E}(t)=r_{2} E(t)\left(1-\frac{E(t)}{K_{2}}\right)-\sigma_{21} S(t) E(t)-\delta_{2} X(t) E(t)-q_{2} F_{2} E(t) \\
\dot{X}(t)=\alpha \delta_{1} X(t) S(t)+\beta \delta_{2} X(t) E(t)-d X(t)-q_{3} F_{3} X(t)
\end{array}\right.
$$

Subject to the initial conditions $(*)$.

The solution of the bioeconomic system (2) is given by:
$\left\{\begin{array}{l}S=a_{11} F_{1}+a_{12} F_{2}+a_{13} F_{3}+S^{*} \\ E=a_{21} F_{1}+a_{22} F_{2}+a_{23} F_{3}+E^{*} \\ X=a_{31} F_{1}+a_{32} F_{2}+a_{33} F_{3}+X^{*}\end{array}\right.$

where

$$
\left\{\begin{array}{l}
a_{11}=\frac{K_{1} \beta \delta_{2}^{2} K_{2} q_{1}}{\alpha \delta_{1}^{2} K_{1} r_{2}+\beta \delta_{2}^{2} K_{2} r_{1}-\alpha \delta_{1} \delta_{2} K_{1} K_{2} \sigma_{12}-\beta \delta_{1} \delta_{2} K_{1} K_{2} \sigma_{21}} \\
a_{12}=-\frac{K_{1} \beta \delta_{1} \delta_{2} K_{2} q_{2}}{\alpha \delta_{1}^{2} K_{1} r_{2}+\beta \delta_{2}^{2} K_{2} r_{1}-\alpha \delta_{1} \delta_{2} K_{1} K_{2} \sigma_{12}-\beta \delta_{1} \delta_{2} K_{1} K_{2} \sigma_{21}} \\
a_{13}=-\frac{K_{1}\left(\delta_{1} r_{2}-\delta_{2} K_{2} \alpha_{12}\right) q_{3}}{\alpha \delta_{1}^{2} K_{1} r_{2}+\beta \delta_{2}^{2} K_{2} r_{1}-\alpha \delta_{1} \delta_{2} K_{1} K_{2} \sigma_{12}-\beta \delta_{1} \delta_{2} K_{1} K_{2} \sigma_{21}} \\
a_{21}=-\frac{K_{2} \alpha \delta_{1} \delta_{2} K_{1} q_{1}}{\alpha \delta_{1}^{2} K_{1} r_{2}+\beta \delta_{2}^{2} K_{2} r_{1}-\alpha \delta_{1} \delta_{2} K_{1} K_{2} \sigma_{12}-\beta \delta_{1} \delta_{2} K_{1} K_{2} \sigma_{21}} \\
a_{22}=\frac{K_{2} \alpha \delta_{1}^{2} K_{1} q_{2}}{\alpha \delta_{1}^{2} K_{1} r_{2}+\beta \delta_{2}^{2} K_{2} r_{1}-\alpha \delta_{1} \delta_{2} K_{1} K_{2} \sigma_{12}-\beta \delta_{1} \delta_{2} K_{1} K_{2} \sigma_{21}} \\
a_{23}=-\frac{K_{2}\left(\delta_{2} r_{1}-\delta_{1} K_{1} \alpha_{21}\right) q_{3}}{\alpha \delta_{1}^{2} K_{1} r_{2}+\beta \delta_{2}^{2} K_{2} r_{1}-\alpha \delta_{1} \delta_{2} K_{1} K_{2} \sigma_{12}-\beta \delta_{1} \delta_{2} K_{1} K_{2} \sigma_{21}} \\
a_{31}=\frac{K_{1}\left(\alpha \delta_{1} r_{2}-\beta \delta_{2} K_{2} \alpha_{21}\right) q_{1}}{\alpha \delta_{1}^{2} K_{1} r_{2}+\beta \delta_{2}^{2} K_{2} r_{1}-\alpha \delta_{1} \delta_{2} K_{1} K_{2} \sigma_{12}-\beta \delta_{1} \delta_{2} K_{1} K_{2} \sigma_{21}} \\
a_{32}=-\frac{K_{2}\left(\alpha \delta_{1} K_{1} \sigma_{12}-\beta \delta_{2} r_{1}\right) q_{2}}{\alpha \delta_{1}^{2} K_{1} r_{2}+\beta \delta_{2}^{2} K_{2} r_{1}-\alpha \delta_{1} \delta_{2} K_{1} K_{2} \sigma_{12}-\beta \delta_{1} \delta_{2} K_{1} K_{2} \sigma_{21}} \\
a_{33}=-\frac{\left(K_{1} K_{2} c_{12} \sigma_{12}-r_{1} r_{2}\right) q_{3}}{\alpha \delta_{1}^{2} K_{1} r_{2}+\beta \delta_{2}^{2} K_{2} r_{1}-\alpha \delta_{1} \delta_{2} K_{1} K_{2} \sigma_{12}-\beta \delta_{1} \delta_{2} K_{1} K_{2} \sigma_{21}}
\end{array}\right.
$$

and

$\left\{\begin{array}{l}S^{*}=K_{1} \frac{d \delta_{1} r_{2}+\beta \delta_{2}^{2} K_{2} r_{1}-d \delta_{2} K_{2} \sigma_{12}-\beta \delta_{1} \delta_{2} K_{2} r_{2}}{\alpha \delta_{1}^{2} K_{1} r_{2}+\beta \delta_{2}^{2} K_{2} r_{1}-\alpha \delta_{1} \delta_{2} K_{1} K_{2} \sigma_{12}-\beta \delta_{1} \delta_{2} K_{1} K_{2} \sigma_{21}} \\ E^{*}=\frac{\left(d \delta_{2} r_{1}+\alpha \delta_{1}^{2} K_{1} r_{2}-d \delta_{1} K_{1} \sigma_{21}-\alpha \delta_{1} \delta_{2} K_{1} r_{1}\right) K_{2}}{\alpha \delta_{1}^{2} K_{1} r_{2}+\beta \delta_{2}^{2} K_{2} r_{1}-\alpha \delta_{1} \delta_{2} K_{1} K_{2} \sigma_{12}-\beta \delta_{1} \delta_{2} K_{1} K_{2} \sigma_{21}} \\ X^{*}=\frac{-d r_{1} r_{2}-\alpha \delta_{1} K_{1} K_{2} r_{2} \sigma_{12}+d K_{1} K_{2} \sigma_{12} \sigma_{21}+\alpha \delta_{1} K_{1} r_{1} r_{2}+\beta \delta_{2} K_{2} r_{1} r_{2}-\beta \delta_{2} K_{1} K_{2} r_{1} \sigma_{21}}{\alpha \delta_{1}^{2} K_{1} r_{2}+\beta \delta_{2}^{2} K_{2} r_{1}-\alpha \delta_{1} \delta_{2} K_{1} K_{2} \sigma_{12}-\beta \delta_{1} \delta_{2} K_{1} K_{2} \sigma_{21}}\end{array}\right.$

We can note that this last solution can be written in a matrix form if we take into consideration the following notation: $Y=(S, E, X)^{T}, F=\left(F_{1}, F_{2}, F_{3}\right)^{T}, A=(-a)_{1 \leq i j \leq 3}$ and $Y^{*}=\left(S^{*}, E^{*}, X^{*}\right)^{T}$. Then, the matrix form is as follow: $Y=Y^{*}-A F$.

We now move on to maximizing the profits of fishermen by taking into account the conservation of the biodiversity of these species and by adding the effects of high and low tides in the fishing effort provided by these fishermen who exploit these species. For this, we first calculate the profit. According to Gordon's economic theory (Rossiter 1961): The profit $\Pi=$ Total Revenue (TR)-Total Cost (TC). In our study, the profit will be taken in 12 months by seiner fleets.

The Total Revenue (TR) is obtained by multiplying the number of catches by the price of the unit species and the 


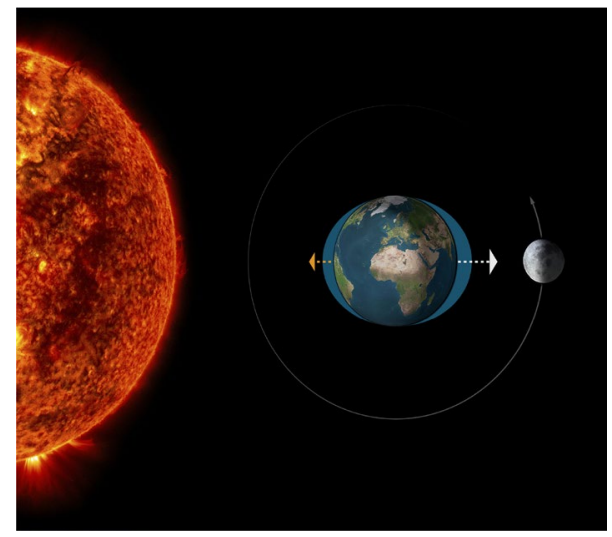

Fig. 8 Full moon (spring) tides

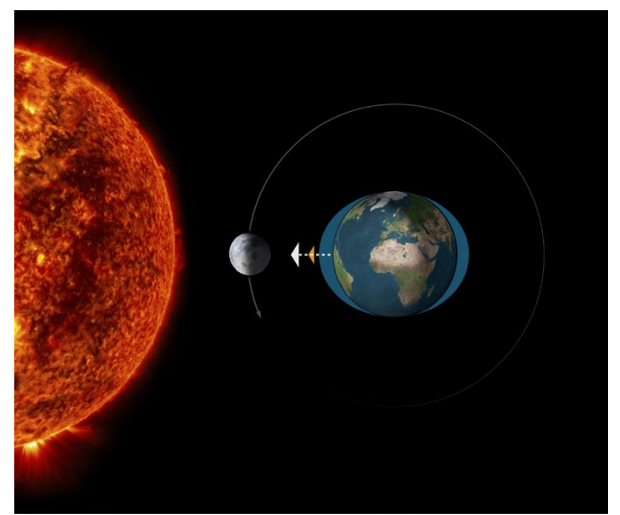

Fig. 9 New moon (spring) tides

Total Cost (TC) is the total measure of the expenses associated with the fishing activity. From the above, the expression of the profit of seiners $j$ is given by:

$\Pi=\sum_{i=1}^{12} \pi_{i j}=\sum_{i=1}^{12}\left(T R_{i j}-(T C)_{i j}\right)$

where $\pi_{i j}$ is the profit of seiner $j$ during the month $i$.

There are two classifications to define the types of tides. The first of these is the measurement of the height of the tide. The second is the phase of the moon, which is directly related to the average action of the fish.

1. According to the height of the tide there are two types:

- High tide when the water in the sea reaches the highest level in the tidal cycle.

- Low tide when the sea water reaches the minimum height in the tidal cycle.

Normally, two high seas and two low seas occur per lunar day; since, at the same time as the Moon lifts the

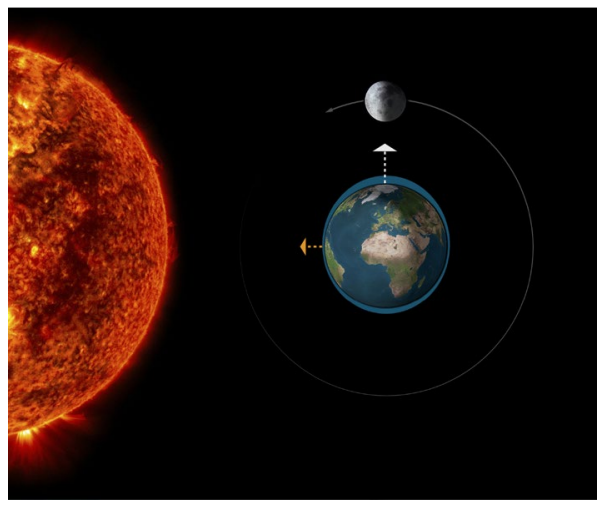

Fig. 10 Last quarter (dead water tides)

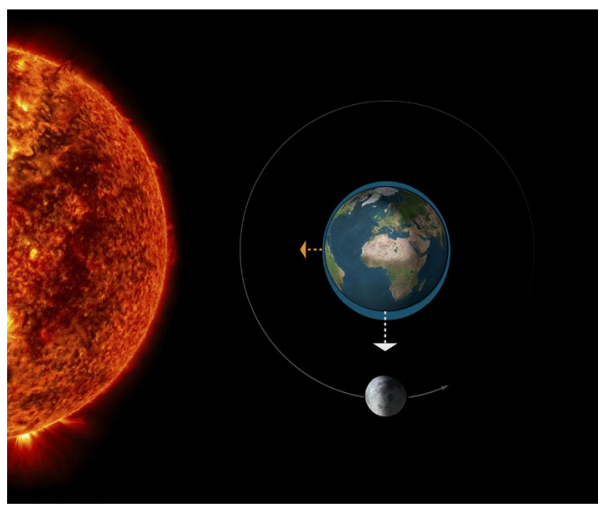

Fig. 11 First quarter (dead water tides)

water on the side of the Earth where it is located, it also separates the Earth from the water on the opposite side.

The result is that water rises above the earth's surface on two diametrically opposed sides of the planet.

2. According to the phase of the moon:

In accordance with the lunar phase, we distinguish two types of tide:

- Spring tides or syzygy

During the full moon and new moon phases, the Moon and the Sun are aligned and their effects combine. These are spring tides. We observe on the tide table the large coefficient of the latter when the two stars are aligned.

An increase in fish activity during spring tides has been verified; especially if the latter coincide with dawn or dusk, these being the most favorable days for fishing (Figs. 8, 9).

- Neap or quadrature tides

During the phases of the first quarter and the last quarter, the effects are on the contrary nil, which produces tides of smaller amplitude (lower tidal coefficient), called neap tides. 
Movement in the seabed is generally less and normally these are less favorable days for fishing than spring tide days (Figs. 10, 11).

The final formula of profit is given by:

$$
\begin{aligned}
\Pi & =\sum_{i=1}^{12}\left[\left(T R_{i j}-(T C)_{i j}\right)\right] \\
& =\sum_{i=1}^{12}\left\langle F^{i j},-p q A F^{i j}+p q Y^{*}-c^{i j}-p q A \sum_{k \neq j, k=1}^{n} F^{i k}\right\rangle
\end{aligned}
$$

where $p=\left(p_{1}, p_{2}, p_{3}\right)^{T}$ the prices per unit harvested biomasses of Sardina pilchardus, Engraulis encrasicolus and Xiphias gladius respectively, $F^{i j}=\left(F_{1 j}^{(i)}, F_{2 j}^{(i)}, F_{3 j}^{(i)}\right)^{T}$ with $F_{m j}^{(i)}$ is the fishing effort dedicated to exploit the marine population $m$ by seiner $j$ during the month $i$ and $c^{i j}$ is the constant cost per unit of harvesting effort.

As constraint of the bioeconomic model we should have a strictly positive biomass of all the marine fish populations, in mathematical words, we must have the following inequality

$Y=Y^{*}-A F \geq Y_{0} \Leftrightarrow A F^{i j} \leq A F^{i m}+Y^{*}$

(for coastal trawler $j$ )

To determine the mathematical expression of fishing effort that maximizes each coastal trawler profit $j$, we use the generelized Nash equilibrium problem. By definition a Nash equilibrium exists when no coastal trawler would take a different action as long as every other coastal trawler remains the same. This problem can be translated into mathematical problems of maximization.

The essential conditions of Karush -Kuhn -Tucker applied to our problem require that if $F^{i j}$ is a solution of the $\operatorname{problem}(P)$, then there exist constants $\left(\lambda^{i j}, u^{i j}, v^{i j}\right) \in\left(\mathbb{R}_{+}^{3}\right)^{3}$ such that:

$\left\{\begin{array}{l}2 p q A F^{i j}+c^{i j}-p q Y^{*}+p q A \sum_{k \neq j, k=1}^{n} F^{i k}-\lambda^{i j}+A^{T} v^{i j}=0 \\ A F^{i j}+u^{i j}=Y^{*} A \sum_{k \neq j, k=1}^{n} F^{i k} \\ \left\langle\lambda^{i j}, F^{i j}\right\rangle=\left\langle v^{i j}, u^{i j}\right\rangle=0\end{array}\right.$

This problem can be translated to a Linear Complementarity Problem (LCP) which consists in finding the two vectors $z, w \in \mathbb{R}_{+}^{3(n+1)}$ such that: $w=M z+l$ which satisfies the following conditions:

$\left\{\begin{array}{l}z \geq 0 \\ M z+l \geq 0 \\ z, w=0\end{array}\right.$

To show that $L C P(M, l)$ has a unique solution, we show that the matrix $M$ is a $P$-matrix.[6]. We follow the same calculation cited in [7] we find the generalized Nash equilibrium problem admits one and onlyone solution. This equilibrium solution is given by:

$F^{i j}=\frac{1}{n+1} A^{-1}\left(Y^{*}-\frac{c^{i j}}{p_{j} q}\right)$

Therefore, the fishing effort that maximizes the profit of coastal trawler $j$ during the month $i$ for catching Sardina pilchardus, Xiphias gladius and Engraulis encrasicolus respectively, is given by:

$\left\{\begin{array}{l}F_{1}^{i j}=\frac{1}{n+1}\left[\frac{r_{1}}{K_{1} q_{1}}\left(S^{*}-\frac{c^{i j}}{p_{1 j} q_{1}}\right)+\frac{\sigma_{12}}{q_{1}}\left(E^{*}-\frac{c^{i j}}{p_{2} q_{2}}\right)+\frac{\delta_{1}}{q_{1}}\left(X^{*}-\frac{c^{i j}}{p_{3} q_{3}}\right)\right] \\ F_{2}^{i j}=\frac{1}{n+1}\left[\frac{\sigma_{21}}{q_{2}}\left(S^{*}-\frac{c^{i j}}{p_{1 j} q_{1}}\right)+\frac{r_{2}}{K_{2} q_{2}}\left(E^{*}-\frac{c^{i j}}{p_{2} q_{2}}\right)+\frac{\delta_{2}}{q_{2}}\left(X^{*}-\frac{c^{i j}}{p_{3} q_{3}}\right)\right] \\ F_{3}^{i j}=\frac{1}{n+1}\left[\alpha \frac{\delta_{1}}{q_{3}}\left(\frac{c^{i j}}{p_{1 j} q_{1}}-S^{*}\right)+\beta \frac{\delta_{2}}{q_{3}}\left(\frac{c^{i j}}{p_{2} q_{2}}-E^{*}\right)\right]\end{array}\right.$

\section{Numerical Simulation}

In this part, we will see the effect of high and low tides on the fishing effort according to the tidal coefficient table then we will compare these results with those obtained without the effect of tides on fishing effort. For obtaining the results we use MATLAB and Scientific Workplace.

In the tide tables (Fig. 12) appear tidal coefficients (in Casablanca) for the whole year 2020, which indicate the magnitude of the expected tide (the difference in height between consecutive high seas and low seas of a place) (https://mareespeche.com/af/marocco-atlantic/casablanca 2021).

$z=\left(\begin{array}{l}F^{i 1} \\ \vdots \\ F^{i n} \\ 0\end{array}\right), w=\left(\begin{array}{l}\lambda^{i 1} \\ \vdots \\ \lambda^{i n} \\ u\end{array}\right), l=\left(\begin{array}{l}c^{i 1}-p q Y^{*} \\ \vdots \\ c^{i n}-p q Y^{*} \\ 0\end{array}\right), M=\left(\begin{array}{lllll}2 p q A & p q A & \cdots & p q A & A^{T} \\ p q A & 2 p q A & \cdots & \vdots & A^{T} \\ \vdots & \vdots & \ddots & p q A & \vdots \\ p q A & \cdots & p q A & 2 p q A & A^{T} \\ -A & \cdots & \cdots & -A & I\end{array}\right)$ 


\begin{tabular}{|c|c|c|c|c|c|c|c|c|c|c|c|c|}
\hline JOUR & JAN & FEV & MAR & AVR & MAI & JUIN & JUIL & $\mathrm{AOU}$ & SEP & OGT & NOV & DEC \\
\hline 1 & 78,76 & 86,83 & $104 / 101$ & 84,75 & 63,56 & $49 / 48$ & $50 \cdot 48$ & $39 / 38$ & $36 / 40$ & $45 / 52$ & 77785 & $86 / 91$ \\
\hline 2 & 75,73 & 79,74 & $97 / 92$ & $67 / 58$ & 50,46 & $47 / 48$ & 47,46 & 38,40 & 46,52 & 60,68 & 92,98 & $95 \cdot 99$ \\
\hline 3 & 70,68 & $69 / 64$ & $85 / 78$ & $51 / 45$ & $43 / 43$ & $49 / 51$ & 46,47 & $42: 46$ & 58,64 & 75,83 & $102 / 106$ & $100: 101$ \\
\hline 4 & $66 / 63$ & 60,56 & 70,63 & $41 / 40$ & $44 / 47$ & $54 / 56$ & 49,50 & 50,54 & $70, \pi 7$ & 89,96 & $108 / 109$ & 101.99 \\
\hline 5 & $62 / 60$ & $53 / 51$ & $55 / 49$ & 42,45 & $51 / 55$ & $59 / 61$ & $53 / 55$ & 58,63 & 82,88 & $101 / 105$ & $107 / 105$ & $96 / 92$ \\
\hline 6 & 60,60 & 52,54 & $45 / 43$ & 50,56 & 59,63 & 64,66 & 58,60 & $67: 77$ & 92,96 & $108 / 109$ & $101 / 95$ & 88.82 \\
\hline 7 & 60,62 & 57,62 & $43 / 46$ & $61 / 67$ & $67 / 70$ & 68,69 & $63 / 65$ & $75 / 79$ & $99 / 101$ & $109: 107$ & $89: 82$ & 77,71 \\
\hline 8 & 64.67 & $66: 71$ & $51 / 57$ & 72,76 & $73 / 76$ & 711,72 & 68,70 & 82,84 & $101 / 101$ & $103 / 98$ & 74.66 & $66: 61$ \\
\hline 9 & 70,73 & $76 / 80$ & 62,68 & 80,83 & $78 / 79$ & 73,73 & 7273 & 86,88 & 99,96 & $92 / 85$ & $59 / 53$ & 56,53 \\
\hline 10 & $77 / 80$ & 83,86 & $73 / 78$ & 85,87 & 80,80 & 73,73 & 74,75 & 88,88 & 91.86 & 77,68 & $48 / 45$ & $51 / 49$ \\
\hline 11 & 83,85 & $88 / 90$ & $82 ; 86$ & 88.88 & $80 / 79$ & 72771 & $75 / 75$ & 87,86 & 79.72 & 60,52 & $44 / 46$ & $49 \cdot 50$ \\
\hline 12 & $87 / 88$ & 90,90 & $88 / 90$ & $87 / 86$ & 78,76 & $69 / 68$ & 75,74 & 83,80 & $65 / 58$ & 46,42 & $48 \cdot 52$ & $51 / 53$ \\
\hline 13 & $89: 88$ & $88: 86$ & $91 / 91$ & $84 / 81$ & $74 / 72$ & 66,63 & 73.72 & $76: 72$ & $51 / 46$ & $41 / 43$ & 56,60 & $55: 57$ \\
\hline 14 & $87 / 85$ & $84 / 80$ & 90,89 & 78,74 & 69,65 & 61,59 & 70,68 & $67 / 62$ & $44 / 44$ & $46 / 51$ & 64,68 & $59 / 62$ \\
\hline 15 & 83,80 & $77 / 72$ & 86,83 & 70,66 & 6258 & $57 / 55$ & 67,65 & 58,54 & 46,51 & 57,63 & 7275 & 64,66 \\
\hline 16 & 76,72 & 67,62 & 80,76 & $61 / 56$ & 54,50 & 54,53 & 63.61 & 52,51 & 57,63 & 69,74 & $77 / 79$ & $68 / 69$ \\
\hline 17 & $68: 64$ & 57,52 & $71 / 66$ & $51 / 46$ & 46,44 & 53,55 & 60,60 & 52555 & 69,75 & 79,83 & $80: 81$ & $71: 72$ \\
\hline 18 & $60 / 55$ & $47 / 42$ & $61 / 55$ & $41 / 37$ & $42 / 41$ & $57 / 60$ & 60,61 & $59 / 64$ & 80,85 & 86.88 & $81 / 81$ & 72,73 \\
\hline 19 & $51 / 47$ & $38 / 34$ & $49 / 44$ & $34 / 33$ & $42 / 45$ & $63 / 67$ & 62,65 & 69,75 & 89,92 & 89,90 & $80: 78$ & 73,72 \\
\hline 20 & $44 / 41$ & $32 / 32$ & $38 / 34$ & $34 / 37$ & 50,55 & 71,75 & 68,71 & 80,84 & 93,94 & 90,89 & 76,74 & $71 / 70$ \\
\hline 21 & $39 / 38$ & $34: 37$ & $31 / 29$ & $43: 50$ & 61,68 & 79,83 & $75 / 79$ & 88,91 & 94.93 & $87 / 85$ & 71,68 & $69 \cdot 67$ \\
\hline 22 & $39 / 40$ & 42,48 & $31 / 34$ & $57 / 65$ & 75,81 & 86,89 & $82: 85$ & $93: 93$ & 91.88 & 8278 & $65 / 61$ & $65 \cdot 63$ \\
\hline 23 & $42 / 46$ & $54 / 61$ & $40 / 46$ & 73,82 & $87 / 93$ & $91 / 92$ & $88 / 89$ & 93,92 & 85.81 & 74,69 & $57 / 53$ & 60.58 \\
\hline 24 & 50,54 & 67774 & 54,62 & $89: 96$ & $97 / 100$ & $93: 92$ & $90: 90$ & 90,87 & 76,71 & 64,59 & $49 / 46$ & 56,54 \\
\hline 25 & $58 / 63$ & $81 / 87$ & 70,78 & $102: 107$ & 102103 & 91,89 & 89.88 & $84: 80$ & 65,59 & $54 / 49$ & $43 \times 40$ & 53,52 \\
\hline 26 & 68,72 & $92 / 97$ & $86 / 93$ & $110: 111$ & $102 / 100$ & $87 / 83$ & $85 / 82$ & 75,70 & $53 / 47$ & $43 / 38$ & $39 / 40$ & 52,52 \\
\hline 27 & $77 / 80$ & $101 / 104$ & $100 / 105$ & $111 / 109$ & $97: 93$ & 80,76 & $79 / 75$ & 64.59 & $41 / 36$ & $34 / 31$ & $42 / 45$ & 54,56 \\
\hline 28 & $84 / 87$ & $105 / 105$ & $109 / 112$ & $106 / 100$ & 88,83 & 71,67 & 70,66 & $53 / 47$ & 32229 & 30,32 & 50,56 & 59,62 \\
\hline 29 & $89 / 91$ & I & $113 / 112$ & 94,87 & 77,71 & 63,59 & 61,56 & $42 / 37$ & $28 / 29$ & $35 / 40$ & 62,68 & 66,70 \\
\hline 30 & $91 / 91$ & 1 & $109 / 105$ & 79,71 & 65,60 & 56,52 & 52,47 & $33 / 31$ & $33 / 39$ & 47,54 & 75,81 & $75: 79$ \\
\hline 31 & $90: 89$ & f & $99 / 92$ & j & $55 / 52$ & t & $\Delta 4 / 41$ & $31 / 32$ & i & 6270 & , & 83,87 \\
\hline
\end{tabular}

Fig. 12 The boxes in green show the coefficients of low tides, in yellow those of average tides, in orange the high tides and in pink the coefficients of the highest tides. [Coefficient $12 \mathrm{am} /$ Coefficient $12 \mathrm{pm}$ ]

Fig. 13 Fishing activity according to the months of the year 2020
Fishing activity

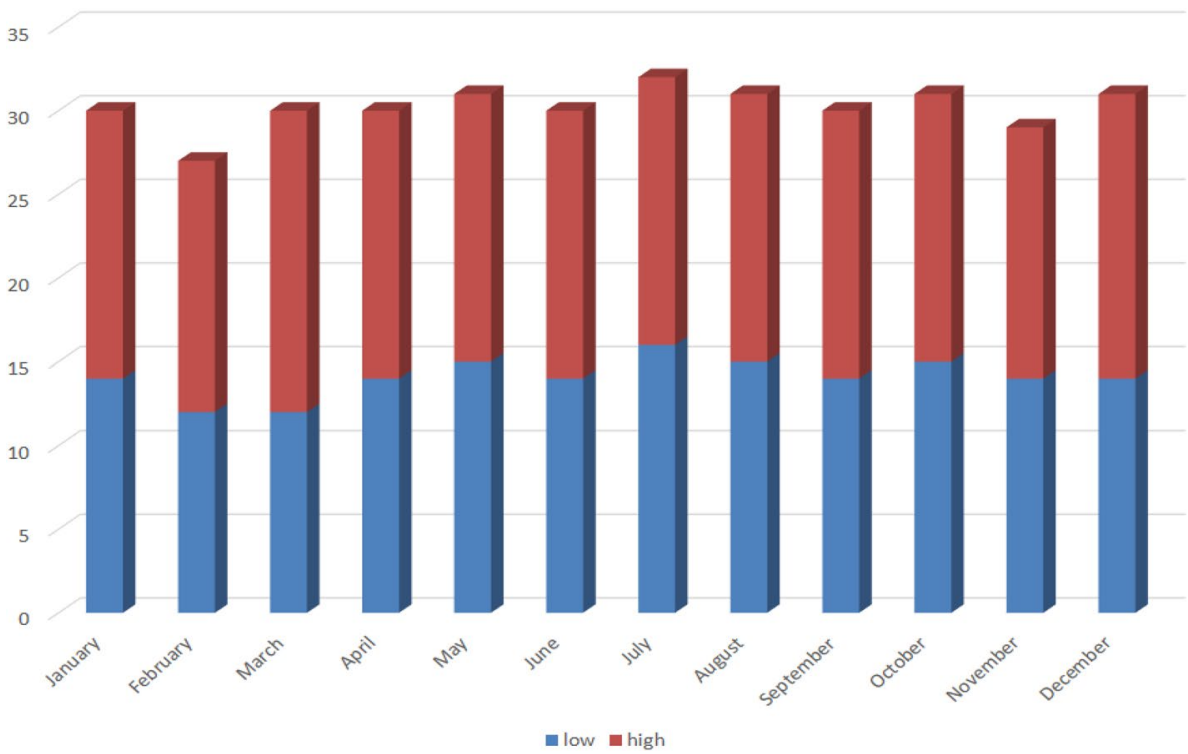

The maximum possible tidal coefficient is 120 , which corresponds to the greatest high tide or low tide that can be given excluding meteorological effects. The tidal coefficients are calculated from the following variables of the sun and the moon: right ascension, declination, parallax and distance from the Earth to the star.

The following graph (Fig. 13) represents the number of days of fishing activity (low or high) as a function of the tidal coefficient.
The Figs. 12, 13 show the fishing effort suggestions that fishermen must provide during the year 2020 to ensure the sustainability of the three marine populations. According to the latest statistics provided by the INRH, for 3087 fishing units of which 435 purse seiners provide a fishing effort equal to 86,811 (trips), taking into account the tidal coefficients in the fishing effort for this same effort the catches made are 574,260 (tons) species. However, for the same 
Table 1 The average of fishing activity during each months on the year 2020

\begin{tabular}{ll}
\hline Months & Fishing activity \\
\hline January & 0.54 \\
February & 0.6 \\
March & 0.7 \\
April & 0.56 \\
May & 0.48 \\
June & 0.43 \\
July & 0.3 \\
August & 0.51 \\
September & 0.64 \\
October & 0.5 \\
November & 0.4 \\
December & 0.55 \\
\hline
\end{tabular}

number of purse seiners but without taking into account the changes in the tides, the effort provided by the purse seiners is found to be 89,830 (trips) to catch 6399.7 (tons) species.

By comparison of the two results: the results that we obtained taking into account the tidal coefficients in the fishing effort and the latest data declared by the INRH 2016, 2017 that there are no big differences and the results are almost the same. This shows the relevance and the reality of this study and will help us to give the best proposals and suggestions for the future.
The Table 1 gives us the percentage of access for fishing. We notice that for the months of March, access for fishing is very high, followed by the months of February and September with a high access for fishing. The months with average access are January, April, August, October and December, on the other hand, for the rest of the months of the year 2020: May, June and November we notice that they have the lowest access for fishing.

However, the highest level reached by the sea during a tidal cycle known by high tides normally occurs at the spring and autumn equinoxes more precisely, the months of March and September. These tides are highly beneficial for the fishing of many fish. Since the current "hits" at the break, the seabed and the marine nutrients are stirred. This phenomenon therefore attracts many fish which take advantage of these tides to feed themselves. The fish stand there to hunt. They also take advantage of the current of the rising tide to enter the baïnes, which are kinds of cavities between sandbanks, to feed themselves, so it is easier to catch them. This allows us to explain the fact that the access for fishing was very high for the month of March (0.7) and high for the month of September (0.64) which is due to the high tides produced in the spring seasons and fall.

In contrast, the lowest tides of the year normally occur at the winter and summer solstices, these are the months of December and June. Where the poor access for fishing
Fig. 14 Influence of tides on catches

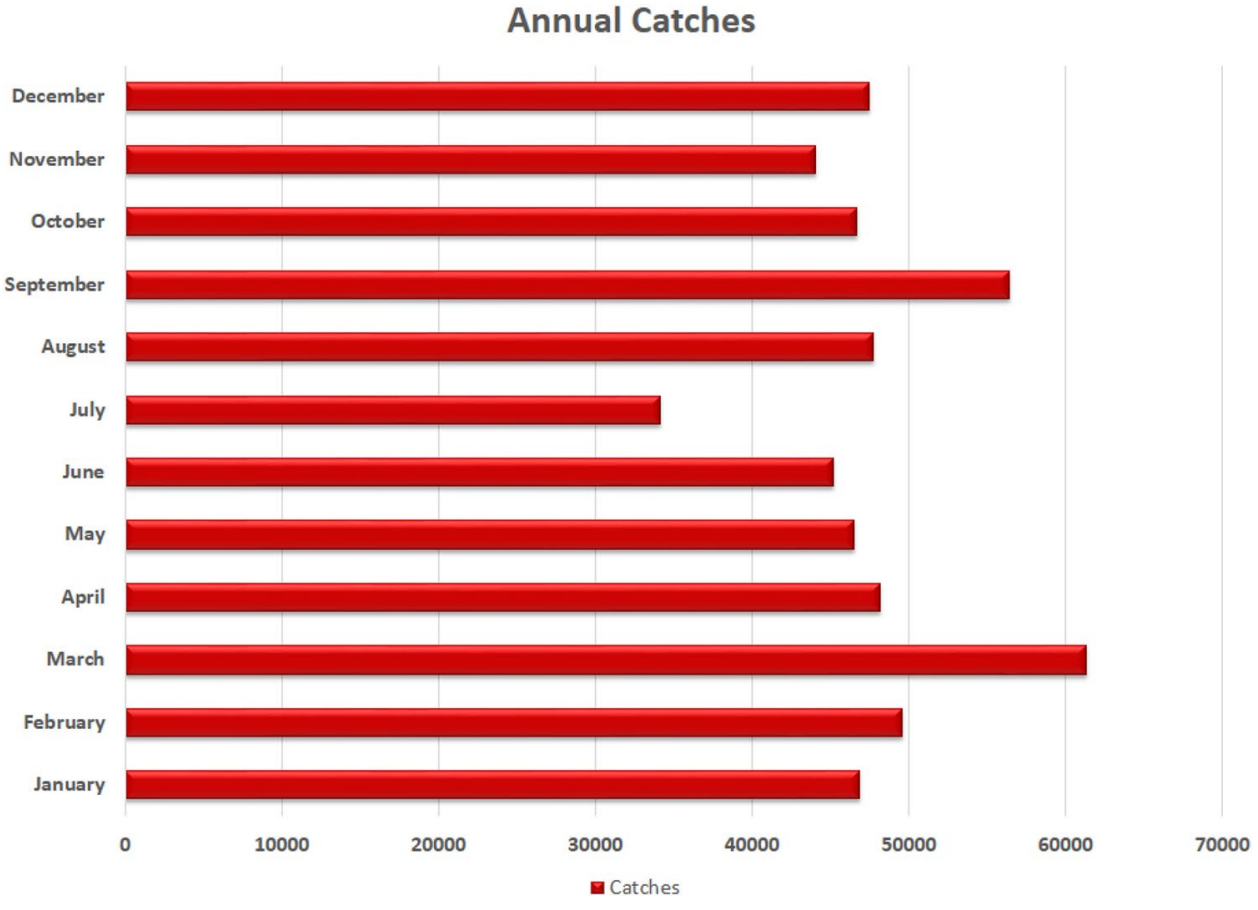


Fig. 15 Influence of tides on fishing effort

Fig. 16 Influence of the tides on profits

\section{Annual Fishing Effort}

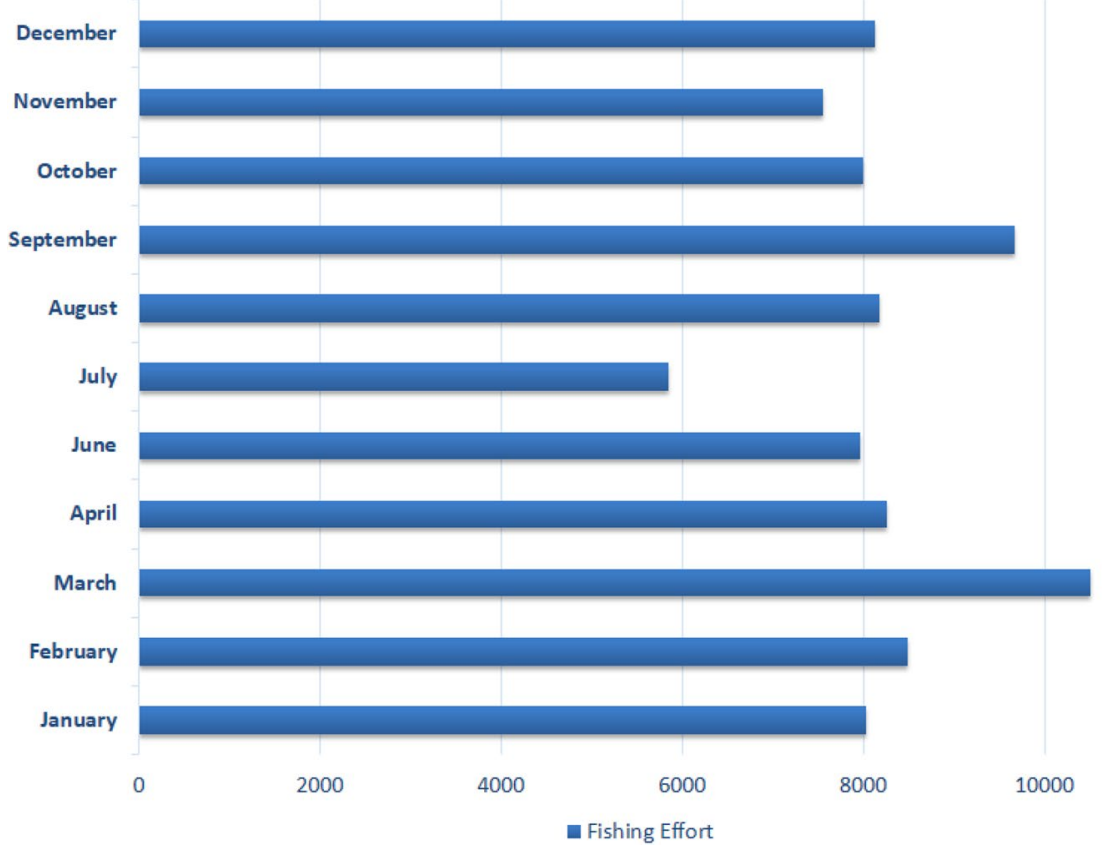

Annual Profits

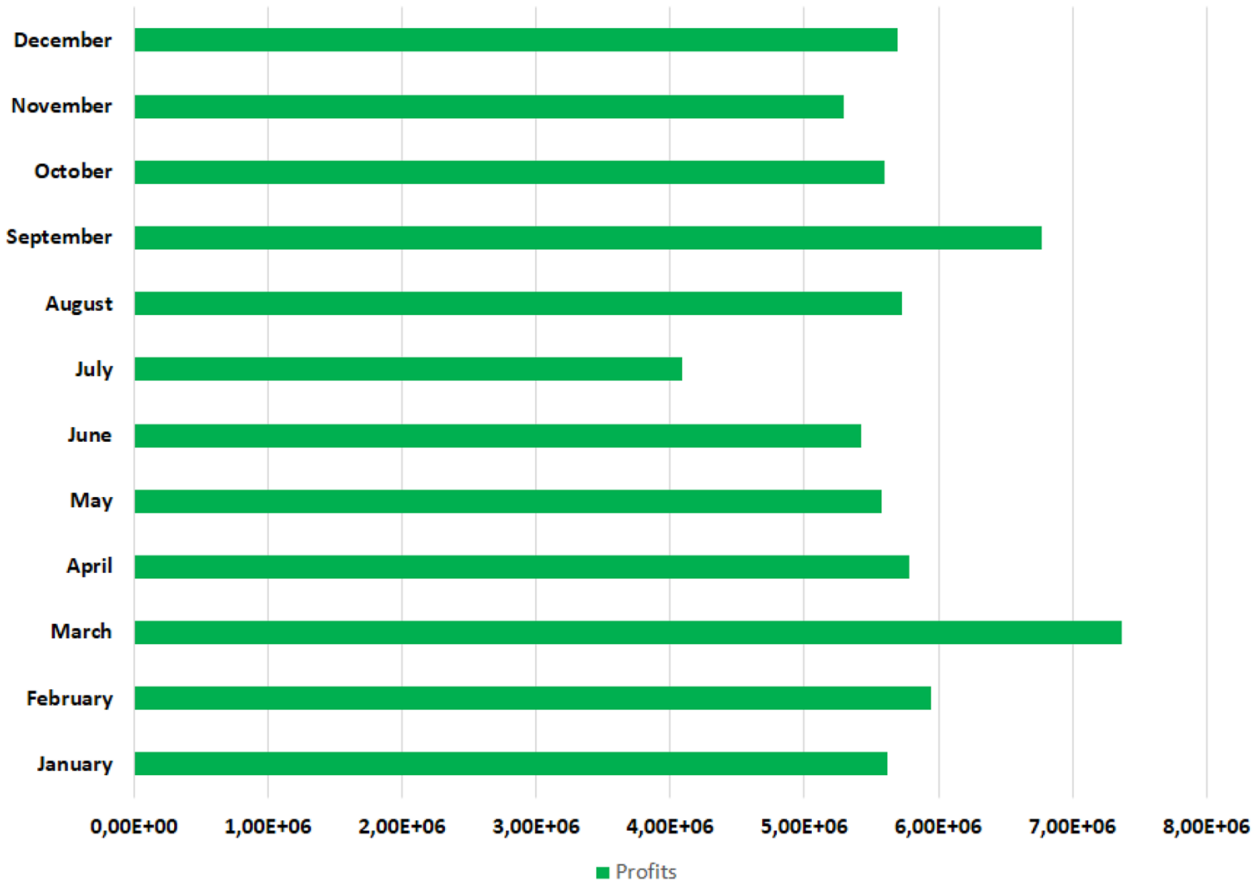

which was noticed in these two months due mainly to the low tides produced which do not give results because these are the corners where the fish only hunt when the current is present.
Obviously, when the tides influence the fishing effort, then there will be a change in the profits as well as in the catches as shown in Figs. 14, 15 and 16. 


\section{Conclusion}

In this work, we saw the importance of introducing the effects of high and low tides in the bioeconomic model on the fishing effort which made it possible to give the best suggestions and proposals for the good times of marine resource exploitation according to the months and days whose tides can increase the catches and profits of fishermen exploiting these resources taking into account the conservation of the biodiversity of marine species which is close to reality and the same statistics declared by the INRH.

\section{Declarations}

Conflict of Interest The authors declare that there are no conflicts of interest regarding the publication of this paper.

Open Access This article is licensed under a Creative Commons Attribution 4.0 International License, which permits use, sharing, adaptation, distribution and reproduction in any medium or format, as long as you give appropriate credit to the original author(s) and the source, provide a link to the Creative Commons licence, and indicate if changes were made. The images or other third party material in this article are included in the article's Creative Commons licence, unless indicated otherwise in a credit line to the material. If material is not included in the article's Creative Commons licence and your intended use is not permitted by statutory regulation or exceeds the permitted use, you will need to obtain permission directly from the copyright holder. To view a copy of this licence, visit http://creativecommons.org/licenses/by/4.0/.

\section{References}

Agmour I, Bentounsi M, Baba N et al (2020) Impact of wind speed on fishing effort. Model Earth Syst Environ 6:1007-1015. https://doi.org/10.1007/s40808-020-00736-7

Agmour I, Baba N, Bentounsi M et al (2021) Mathematical study and optimal control of bioeconomic model concerning harmful dinoflagellate phytoplankton. Comp Appl Math 40:129. https:// doi.org/10.1007/s40314-021-01509-3

Baba N, Agmour I, Achtaich N, El Foutayeni Y (2019) The mathematical study for mortality coefficients of small pelagic species. Commun Math Biol Neurosci 2019

Baba N, Agmour I, El Foutayeni Y, Achtaich N (2021) Bioeconomicepidemiological model of Scomber colias population in the Moroccan Coasts. J Appl Math. https://doi.org/10.1155/2021/ 8892388
Bentounsi M, Agmour I, Achtaich N, El Foutayeni Y (2018) The impact of price on the profits of fishermen exploiting tritrophic prey-predator fish populations. Int J Diff Equ. https://doi.org/10. $1155 / 2018 / 238148$

Clark WC, Gordon RM (1975) The economics of fishing and modern capital theory: a simplified approach. J Environ Econ Manag 2:92-106

Clarke FH, Munro GR (1991) Coastal states, distant water fishing nations and extended jurisdiction: conflicting views of the future. Nat Resour Model 5:345-369

ComptoirDesPêcheurs.com https://comptoirdespecheurs.com/pecheen-mer/932-Grandes-mar\%C3\%A9es-:-Comment-r\%C3\%A9uss ir-sap\%C3\%AAche-ce-Week-End-\%3F

Gordon HS (1954) The economic theory of a common property resource: the fishery. J Polit Econ 62:124-142

Haddon M (2001) Modelling and qualitative methods in fisheries. CRC Press, New York

https://mareespeche.com/af/marocco-atlantic/casablanca

INRH/DP 2017-Rapport annuel de l'Etat des stocks et des pêcheries marocaines 2017. 287 p. Institut National de recherche Halieutique, Casablanca (Maroc)-ISSN: 2509-1727

INRH/DRH 2016-Rapport annuel de l'Etat des stocks et des pêcheries marocaines 2016. $294 \mathrm{p}$

Jones JE, Davies AM (2006) Application of a finite element model (TELEMAC) to computing the wind induced response of the Irish Sea. Cont Shelf Res 26:1519-1541

Olbert AI, Nash S, Cunnane C et al (2013) Tide-surge interactions and their effects on total sea levels in Irish coastal waters. Ocean Dyn 63:599-614. https://doi.org/10.1007/s10236-013-0618-0

Proudman J (1955) The propagation of tide and surge in an estuary. Proc R Soc Lond A231:8-24

Proudman J (1957) Oscillations of tide and surge in an estuary of finite length. J Fluid Mech 2:371-382

Pugh Dt (1987) Tides, surges and mean sea levels a handbook for engineers and scientists. Wiley, Chichester

Quinn TJ, Deriso RB (1999) Quantitative fish dynamics. Oxford University Press, New York

Rossiter JR (1961) Interaction between tide and surge in the Thames. Geophys J R Astron Soc 6:29-53

Schaefer MB (1954) Some aspects of the dynamics of populations important to the management of the commercial marine fisheries. Bull Inter-Am Trop Tuna Comm 1:25-56

Schaefer MB (1957) Some considerations of population dynamics and economics in relation to the management of marine fisheries. $\mathrm{J}$ Fish Res Board Can 14:669-681

Steacy Dopp Hicks, Understanding tides, Center for Operational Oceanographic Products and Services Michael Szabados, Director, December 2006

Trupin A, Wahr J (1990) Spectroscopic analysis of global tide gauge sea level data. Geophys J Intern 100:441-453 